\title{
ENGEVISTA
}

Página da revista: http://www.uff.br/engevista/seer/

\section{Clarificação de efluente proveniente de uma agroindústria do oeste catarinense utilizando extrato de acácia negra (Acácia mearnsii) como coagulante}

\author{
Ana Paula Dariff ${ }^{1}$ \\ Alana Caroline Milan Damo ${ }^{2}$ \\ Aniela Pinto Kempka ${ }^{3}$
}

Resumo: O consumo e, por consequência, a industrialização de alimentos crescem cada vez mais com o passar dos anos, e com isso, a geração de efluentes agroindustriais também se intensifica. Estes efluentes devem ser tratados e dentre os tratamentos químicos convencionais, tem-se a coagulação/floculação, onde são utilizados sais de ferro e alumínio, que tornam o lodo, obtido de efluentes submetidos a estes tratamentos, impróprio para ser disposto no ambiente. Como alternativa, tem-se os coagulantes naturais, oriundos de plantas, como o extrato de Acácia Negra (Acácia mearnsii). O objetivo deste trabalho foi determinar a melhor concentração de coagulante e verificar a influência da velocidade de agitação rápida, velocidade de agitação lenta, tempo de agitação rápida e tempo de agitação lenta na clarificação do efluente e no volume de sólidos decantados, utilizando a técnica de planejamento de experimentos. Os percentuais de clarificação do efluente foram de 56,20\% e 56,53\% para as diluições de $1 \%$ e $2 \%$ do extrato Acácia Negra, respectivamente. A combinação adequada da velocidade de agitação rápida e da velocidade de agitação lenta contribui para o aumento da decantação de sólidos e que o tempo de agitação rápida e o tempo de agitação lenta dentro da faixa testada, não apresentaram efeito estatístico significativo $(\mathrm{p}>0,05)$.

Palavras-chave: Concentração, planejamento experimental, velocidades de agitação, tempo de agitação.

\footnotetext{
${ }^{1}$ UDESC - Universidade do Estado de Santa Catarina

2 UDESC - Universidade do Estado de Santa Catarina

${ }^{3}$ UDESC - Universidade do Estado de Santa Catarina
} 
ISSN: $1415-7314$

ISSN online: 2317-6717

Abstract: The consumption and, consequently, the industrialization of food increases over the years, and with it, the generation of agro-industrial wastewaters also intensifies. These wastewaters must be treated and among conventional chemical treatments, they are coagulation/flocculation, which are used salts of iron and aluminum, which makes the sludge obtained from wastewater subjected to these treatments, inappropriate to be disposed into the environment. Alternatively, can use the natural coagulants, derived from plants such as Acacia Negra extract (Acacia mearnsii). The objective of this study was to determine the optimal concentration of coagulant and the influence the speed of rapid agitation, speed of slow agitation, rapid agitation time and slow agitation time in clarifying the wastewater and the volume of settled solids, using the technique of design of experiments. The percentages of the clarification of the wastewater were $56.20 \%$ and $56.53 \%$ for dilutions of $1 \%$ and $2 \%$ of extract of Acacia Negra, respectively. The appropriate combination of speed of rapid agitation and of the speed of slow agitation contributes to increased decanting of the solids and rapid agitation time and slow agitation time, within the range tested, did not have statistically significant effect ( $p>0,05)$.

Keywords: Concentration, experimental design, stirring speed, stirring time. 


\section{Introdução}

O crescimento significativo das indústrias ocasionou um aumento de investimentos em novas tecnologias para tratamento de resíduos que atendam a legislação ambiental vigente (Lenhari e Hussar, 2010).

A disposição inadequada de resíduos agroindustriais pode ocasionar problemas ao meio ambiente, em especial se despejados efluentes carregados de resíduos orgânicos, que ficam depositados em mananciais de água e provocam a degradação do bioma existente, além de ocasionar sérios danos para a população que necessita de água de qualidade para sobreviver (Edvan e Carneiro, 2011).

Para o tratamento destes efluentes carregados em poluentes orgânicos, o uso de coagulantes químicos é largamente empregado por ser considerado um método eficiente e tradicional de tratamento e clarificação. Mesmo mostrando-se eficientes ao longo de sua utilização para o tratamento de águas residuais, os coagulantes químicos são apontados como causadores de problemas relacionados à saúde humana. Estudos associam sua utilização com o desenvolvimento de doenças como o Alzheimer, demência senil e outras (Choy et al., 2014).

Dos coagulantes químicos utilizados, os sais de ferro e alumínio são comuns, seu uso agrega agentes inorgânicos não biodegradáveis à água ou ao lodo gerado durante o tratamento, características ambientalmente indesejáveis. O lodo inorgânico gerado se torna de difícil manuseio e tratamento por parte das indústrias, sendo assim, necessário buscar coagulantes ambientalmente mais compatíveis (Vaz et al., 2010).

Indústrias químicas e petroquímicas do Brasil e Europa estão empregando polímero de origem vegetal, no lugar do sulfato de alumínio e outros metais para efetuar a etapa de coagulação em estações de tratamento, tanto de lodos industriais quanto de água para o consumo humano. Esta alternativa pode ser muito eficiente para os efluentes da agroindústria e eliminar os problemas decorrentes do uso de sulfato de alumínio e seu descarte (Piantá, 2008).

Dentre os coagulantes naturais que podem ser utilizados, tem-se o extrato obtido da Acácia negra (Acácia mearnsii), obtido através do processo de lixiviação da casca da Acácia. O uso de coagulantes orgânicos naturais traz diversas vantagens como uma menor geração de lodo (menor quantidade) e o lodo gerado ser biodegradável, por não possuir sais de alumínio e ferro, o que possibilita sua compostagem e disposição final (Vaz et al., 2010).

As barreiras que circundam o uso dos coagulantes naturais ainda estão associadas quanto à escassez de estudos mais detalhados sobre sua utilização e efetividade, sua variedade e características (Choy et al., 2014)

Portanto, o presente estudo teve por objetivo verificar diferentes condições operacionais empregadas na clarificação de efluente proveniente de uma agroindústria do Oeste Catarinense, utilizando como coagulante natural o extrato de Acácia Negra (Acácia mearnsii). Para tanto, foram 
testadas diferentes concentrações e verificada a influência da velocidade e do tempo de agitação na coagulação e clarificação do efluente.

\section{Metodologia}

Os experimentos foram realizados no Laboratório de Bioprocessos, do Departamento de Engenharia Alimentos e Engenharia Química (DEAQ) da Universidade do Estado de Santa Catarina (UDESC) em Pinhalzinho/SC.

O efluente utilizado nos ensaios experimentais foi coletado na entrada da Estação de Tratamento de Efluentes (ETE) de uma agroindústria localizada na região oeste de Santa Catarina, não sendo permitida a divulgação de seu nome nem segmento de atuação.

\subsection{Varredura espectral do efluente e clarificação}

A primeira etapa do estudo teve como objetivo realizar uma varredura espectral, buscando verificar qual o comprimento de onda ideal para determinação da clarificação do efluente utilizando espectrofotometria. Para tanto, os valores de absorbância do efluente foram determinados em comprimentos de onda de 325 a $1000 \mathrm{~nm}$, com incrementos de $25 \mathrm{~nm}$.

Para a determinação da clarificação, as amostras de efluente coaguladas e sedimentadas foram analisadas em espectrofotômetro (Pro-Tools, V-1200), sendo obtidos os valores de transmitância no comprimento de onda definido pela varredura espectral (Paula et al., 2009; Pozzobon e Kempka, 2015).

\subsection{Preparo dos experimentos de clarificação e definição da concentração do coagulante}

Para obtenção dos valores de concentração foram utilizadas as metodologias de Cardoso et al. (2008) e Zolett et al. (2012) adaptadas.

As concentrações dos produtos químicos a serem utilizado no processo de coagulação são definidas a partir do volume de água a ser tratada, onde basicamente são utilizadas concentrações de $1,0 \%$ e $2,0 \%$ (Zolett et al., 2012).

Na primeira etapa do estudo, foram testadas as concentrações de 1,0\% e 2,0\% (v/v) de extrato de Acácia negra (Acácia mearnsii - Veta Organic).). Para tanto, a solução a 1\% foi obtida a partir de $1 \mathrm{~mL}$ do coagulante que foi transferido para um balão volumétrico de $100 \mathrm{~mL}$, sendo completado o volume com água destilada. O mesmo procedimento foi realizando para a solução de $2 \%$.

Após a obtenção das soluções do coagulante, foram adicionados $200 \mathrm{~mL}$ do efluente em Erlenmeyers de $250 \mathrm{~mL}$, com volumes da solução coagulante a $1 \%$ e $2 \%$, separadamente, variando de $2 \mathrm{~mL}$ a $20 \mathrm{~mL}$, com incrementos de $2 \mathrm{~mL}$. Os Erlenmeyers contendo o efluente e o volume de coagulante foram colocados em Shaker (Solab). 
Nesta primeira etapa da clarificação foram utilizadas as velocidades rápida e lenta de 150 rpm e 100 rpm, respectivamente, e os tempos de agitação rápida e lenta de 1 minuto e 20 minutos, respectivamente (Flores et al., 1998; Cardoso et al., 2008; Pozzobon e Kempka, 2015).

Para que ocorresse a decantação dos sólidos após a coagulação/floculação, as soluções de efluente e coagulante foram transferidas para provetas graduadas de $300 \mathrm{~mL}$, permanecendo em repouso por 30 minutos para decantação, sendo determinado o volume de sólidos decantados (mL/200mL de efluente).

\subsection{Influência das velocidades e tempos de agitação}

Após a definição da concentração de coagulante, a segunda etapa do estudo foi a verificação da influência da velocidade rápida e da velocidade lenta e do tempo de agitação rápida e tempo de agitação lenta na coagulação do efluente agroindustrial utilizando o extrato de Acácia negra.

Para tanto, amostras de $200 \mathrm{~mL}$ de efluente e $10 \mathrm{~mL}$ de solução coagulante a $2 \%$ foram colocadas em Erlenmeyers de $250 \mathrm{~mL}$ e dispostas em Shaker (Solab) variando a velocidade (rpm) e o tempo (min) de agitação, de acordo com o Delineamento Composto Central Rotacional (DCCR) com pontos axiais, fracionado, mostrado na Tabela 1.

\subsection{Análise Estatística}

A análise estatística dos resultados experimentais foi realizada utilizando o software Statistica ${ }^{\circledR} 10.0$ (Statsoft, Inc.). Foi realizado o Teste de Tukey sendo também avaliados os efeitos isolados e de interação entre as variáveis do planejamento proposto com nível de $95 \%$ de confiabilidade. 
Tabela 1. Delineamento Composto Central Rotacional (DCCR) com pontos axiais, fracionado (valores das variáveis e níveis), utilizado no estudo das velocidades e tempos de agitação para a clarificação do efluente agroindustrial utilizando extrato de Acácia negra (Acácia mearnsii) como

\begin{tabular}{ccccc}
\hline $\begin{array}{c}\text { Experi- } \\
\text { mento }\end{array}$ & $\begin{array}{c}\text { Agitação rápida } \\
\text { (rpm) }\end{array}$ & $\begin{array}{c}\text { Agitação lenta } \\
(\mathbf{r p m})\end{array}$ & $\begin{array}{c}\text { Tempo de } \\
\text { agitação } \\
\text { rápida (min) }\end{array}$ & $\begin{array}{c}\text { Tempo de } \\
\text { agitação } \\
\text { lenta (min) }\end{array}$ \\
\hline E1 & $230(1,00)$ & $120(1,00)$ & $7(1,00)$ & $10(-1,00)$ \\
E2 & $230(1,00)$ & $120(1,00)$ & $3(-1,00)$ & $10(-1,00)$ \\
E3 & $230(1,00)$ & $80(-1,00)$ & $7(1,00)$ & $30(1,00)$ \\
E4 & $170(-1,00)$ & $120(1,00)$ & $3(-1,00)$ & $30(1,00)$ \\
E5 & $230(1,00)$ & $80(-1,00)$ & $3(-1,00)$ & $30(1,00)$ \\
E6 & $170(-1,00)$ & $80(-1,00)$ & $7(1,00)$ & $10(-1,00)$ \\
E7 & $170(-1,00)$ & $120(1,00)$ & $7(1,00)$ & $30(1,00)$ \\
E8 & $170(-1,00)$ & $80(-1,00)$ & $3(-1,00)$ & $10(-1,00)$ \\
E9 & $150(-1,68)$ & $100(0,00)$ & $5(0,00)$ & $20(0,00)$ \\
E10 & $250(1,68)$ & $100(0,00)$ & $5(0,00)$ & $20(0,00)$ \\
E11 & $200(0,00)$ & $66(-1,68)$ & $5(0,00)$ & $20(0,00)$ \\
E12 & $200(0,00)$ & $134(1,68)$ & $5(0,00)$ & $20(0,00)$ \\
E13 & $200(0,00)$ & $100(0,00)$ & $1,6(-1,68)$ & $20(0,00)$ \\
E14 & $200(0,00)$ & $100(0,00)$ & $8,4(1,68)$ & $20(0,00)$ \\
E15 & $200(0,00)$ & $100(0,00)$ & $5(0,00)$ & $3(-1,68)$ \\
E16 & $200(0,00)$ & $100(0,00)$ & $5(0,00)$ & $37(1,68)$ \\
E17 & $200(0,00)$ & $100(0,00)$ & $5(0,00)$ & $20(0,00)$ \\
E18 & $200(0,00)$ & $100(0,00)$ & $5(0,00)$ & $20(0,00)$ \\
\hline
\end{tabular}

\section{Resultados e discussão}

\subsection{Varredura espectral do efluente}

A Figura 1 mostra o perfil obtido na varredura espectral.

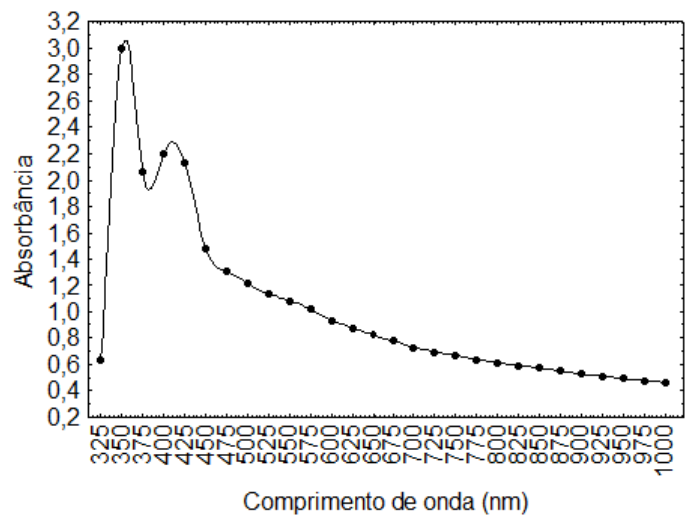

Figura 1. Varredura espectral do efluente agroindustrial.

Verifica-se que o pico de absorbância ocorreu no comprimento de onda de 350nm, sendo este o comprimento de onda utilizado nos demais experimentos para verificação da clarificação do efluente utilizando o coagulante natural. 


\subsection{Concentração de coagulante utilizado na clarificação do efluente agroindustrial}

Na Tabela 2 estão os resultados das médias de clarificação $(\%)$ e sólidos decantados $(\mathrm{mL})$ do efluente agroindustrial após a coagulação e a decantação, utilizando $1 \%$ e 2\% de extrato de Acácia negra (Acácia mearnsii) como coagulante com adição de diferentes volumes.

Para a concentração de $1 \%$, verifica-se, através de Teste de Tukey, que o experimento com adição de $20 \mathrm{~mL}$ de extrato de Acácia negra apresentou a maior clarificação, igual estatisticamente ( $>>0,05)$ ao experimento adicionado de $18 \mathrm{~mL}$ e diferente estatisticamente $(\mathrm{p}<0,05)$ dos demais. Em relação aos sólidos decantados, verifica-se que, a partir da adição de $12 \mathrm{~mL}$ de solução de extrato de Acácia a $1 \%$ não houve diferença significativa.

Para a concentração de $2 \%$, verifica-se, através de Teste de Tukey, que o experimento com adição de $10 \mathrm{~mL}$ de extrato de Acácia negra apresentou a maior clarificação, igual estatisticamente ( $p>0,05)$ aos experimentos adicionados de $8 \mathrm{~mL}$ e $12 \mathrm{~mL}$ e diferente $(\mathrm{p}<0,05)$ dos demais. Em relação aos sólidos decantados, verifica-se que os experimentos com adição de $12 \mathrm{~mL}, 14 \mathrm{~mL}$ e $16 \mathrm{~mL}$ de extrato de Acácia a 2\% não diferiram estatisticamente ( $p>0,05)$.

Os perfis obtidos para a clarificação (\%) (a) e para os sólidos decantados (b) utilizando 1\% e $2 \%$ de extrato de Acácia negra estão mostrados na Figura 2.

Tabela 2. Delineamento Composto Central Rotacional (DCCR) com pontos axiais, fracionado (valores das variáveis e níveis), utilizado no estudo das velocidades e tempos de agitação para a clarificação do efluente agroindustrial utilizando extrato de Acácia negra (Acácia mearnsii) como coagulante.

\begin{tabular}{|c|c|c|c|c|}
\hline \multirow{2}{*}{$\begin{array}{l}\text { Volume de } \\
\text { coagulante } \\
\text { adicionado } \\
(\mathrm{mL})\end{array}$} & \multicolumn{2}{|c|}{ Coagulante 1\% (v/v) } & \multicolumn{2}{|c|}{ Coagulante 2\% (v/v) } \\
\hline & $\begin{array}{c}\text { Clarificação } \\
(\%)\end{array}$ & $\begin{array}{c}\text { Sólidos } \\
\text { decantados } \\
\text { (mL/200mL de } \\
\text { efluente) } \\
\end{array}$ & $\begin{array}{c}\text { Clarificação } \\
(\%)\end{array}$ & $\begin{array}{c}\text { Sólidos } \\
\text { decantados } \\
\text { (mL/200mL de } \\
\text { efluente) }\end{array}$ \\
\hline 2 & $0,00^{\mathrm{a}} \pm 0,00$ & $0,00^{\mathrm{a}} \pm 0,00$ & $0,00^{\mathrm{a}} \pm 0,00$ & $0,00^{\mathrm{a}} \pm 0,00$ \\
\hline 4 & $0,00^{\mathrm{a}} \pm 0,00$ & $0,00^{\mathrm{a}} \pm 0,00$ & $37,17^{c} \pm 1,10$ & $18,00^{\mathrm{b}} \pm 1,00$ \\
\hline 6 & $18,23^{\mathrm{b}} \pm 6,90$ & $20,00^{\mathrm{b}} \pm 5,29$ & $44,70^{\mathrm{d}} \pm 1,45$ & $20,33^{\mathrm{b}} \pm 1,53$ \\
\hline 8 & $32,53^{\mathrm{cd}} \pm 3,03$ & $22,67^{b} \pm 3,06$ & $50,63^{\mathrm{de}} \pm 2,14$ & $27,67^{\mathrm{cd}} \pm 1,53$ \\
\hline 10 & $42,13^{\mathrm{de}} \pm 4,20$ & $23,67^{\mathrm{b}} \pm 0,58$ & $56,53^{\mathrm{e}} \pm 3,35$ & $29,67^{\text {cde }} \pm 0,58$ \\
\hline 12 & $26,77^{\mathrm{bc}} \pm 3,78$ & $33,67^{c} \pm 0,58$ & $49,67^{\mathrm{de}} \pm 1,81$ & $36,00^{\mathrm{f}} \pm 2,00$ \\
\hline 14 & $42,53^{\mathrm{de}} \pm 2,15$ & $40,00^{c} \pm 1,73$ & $45,83^{\mathrm{d}} \pm 2,67$ & $33,00^{\mathrm{ef}} \pm 3,00$ \\
\hline 16 & $46,67^{\mathrm{de}} \pm 1,33$ & $39,00^{c} \pm 2,65$ & $32,70^{\mathrm{c}} \pm 1,15$ & $32,00^{\text {def }} \pm 3,00$ \\
\hline 18 & $53,03^{\mathrm{ef}} \pm 2,51$ & $37,00^{c} \pm 1,00$ & $13,40^{\mathrm{b}} \pm 4,93$ & $28,33^{\text {cde }} \pm 2,08$ \\
\hline 20 & $56,20^{\mathrm{f}} \pm 2,86$ & $38,33^{c} \pm 1,53$ & $1,80^{\mathrm{a}} \pm 0,17$ & $25,67^{c} \pm 0,58$ \\
\hline
\end{tabular}

Médias do percentual de clarificação seguidas de letras maiúsculas diferentes, na horizontal, diferem em nível de $95 \%$ de confiança $(\mathrm{p}<0,05)$ pelo Teste de Tukey. 


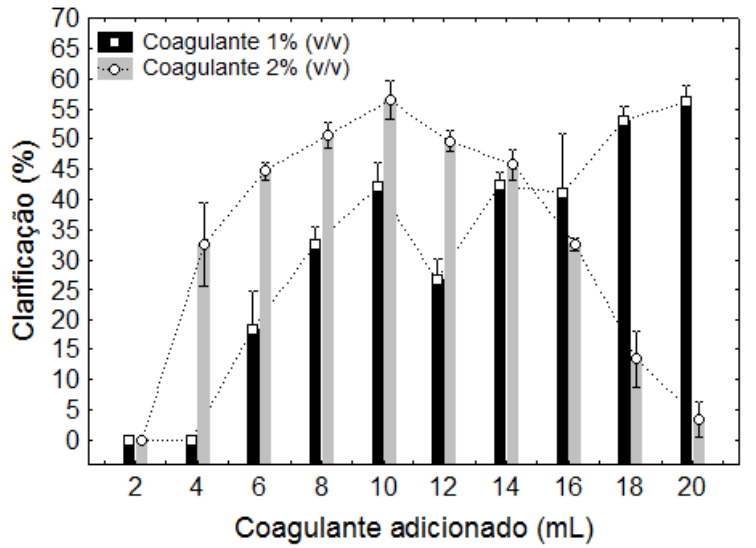

(a)

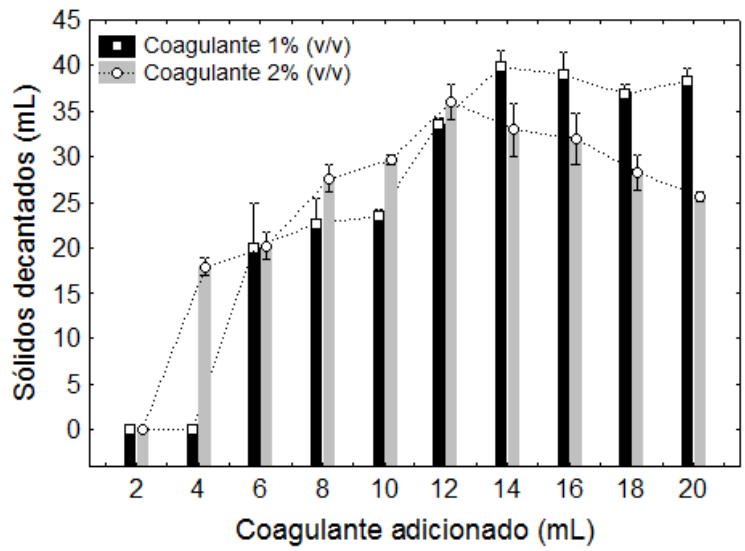

(b)

Figura 2. Perfis de Clarificação (\%) (a) e sólidos decantados (mL/200 mL de efluente) (b) do efluente agroindustrial em relação ao volume de solução de coagulante (Extrato de Acácia negra) a $1 \%$ e $2 \%$ adicionado.

Observa-se na Figura 2a, que para a clarificação (\%) utilizando-se a solução de coagulante a $1 \%$, o maior valor obtido foi quando adicionados $18 \mathrm{~mL}$ e $20 \mathrm{~mL}$. Já para a solução coagulante a $2 \%$, observa-se um pico de máxima clarificação, localizado em $10 \mathrm{~mL}$. Verifica-se, para este efluente, que existe uma relação direta entre a clarificação e a concentração e volume de coagulante adicionado. Dobrando-se a concentração do coagulante, pode-se adicionar a metade do volume do coagulante para obter a mesma clarificação.

Para os sólidos decantados, Figura $2 \mathrm{~b}$, verifica-se que o aumento do volume adicionado do coagulante na concentração de $1 \%$ levou a uma maior decantação de sólidos, sendo o perfil constante a partir de $14 \mathrm{~mL}$. Quando utilizado o coagulante na concentração de $2 \%$, verifica-se que houve um pico de sólidos decantados em $12 \mathrm{~mL}$ e posteriormente um decréscimo.

Os valores obtidos no processo de sólidos decantados tiveram maiores variações, que podem ser decorrentes da diferença dos tipos de sólidos em suspensão e do diâmetro das partículas encontradas no efluente.

O estudo de De Martini e Moruzzi, (2013), demonstrou que no tratamento de águas pluviais o coagulante Acquapol (nome comercial de um coagulante obtido do extrato de Acácia Negra) na concentração de $3 \%$ apresentou os melhores resultados, com remoção de $80 \%$ de remoção de cor aparente e turbidez do efluente.

Para Vaz et al. (2010), os melhores resultados obtidos para o uso do coagulante vegetal Tanfloc (nome comercial de um coagulante obtido do extrato de Acácia Negra) na remoção de turbidez em efluente de galvanoplastia correspondeu à concentração de 400 ppm, com remoção de turbidez de $99,38 \%$.

Nos estudos realizados por Matos et al. (2007) com semente de Moringa para remoção de turbidez de água, observaram maior eficiência na remoção de sólidos suspensos quando foi utilizada a dose de $10 \mathrm{~mL} / \mathrm{L}$, obtendo-se eficiências de remoção de turbidez acima de $90 \%$. 
Para a próxima etapa do estudo utilizou-se a concentração de $2 \%$ de solução de extrato de Acácia negra e o volume de $10 \mathrm{~mL}$ para $200 \mathrm{~mL}$ de efluente agroindustrial.

\subsection{Influência das velocidades rápida e lenta e dos tempos de agitação rápido e lento na clarificação e volume de sólidos do efluente agroindustrial}

Na Tabela 3 são apresentadas as médias da clarificação (\%) e sólidos decantados (mL/200mL de efluente) seguidas dos respectivos desvios padrão para os experimentos do planejamento DCCR. Verifica-se que o maior percentual de clarificação foi obtido para o E9, diferente estatisticamente $(\mathrm{p}<0,05)$ dos demais experimentos. Para os sólidos decantados, verifica-se que os experimentos E6, E8, E13 e E16 são iguais estatisticamente ( $p>0,05)$.

Após a realização do planejamento experimental, foram obtidos os efeitos das variáveis do estudo. Os Diagramas de Pareto, mostrados na Figura 3 apresentam os efeitos lineares (L) e quadráticos $(\mathrm{Q})$ entre as variáveis do planejamento proposto: agitação rápida (AR), agitação lenta (AL), tempo de agitação rápida (TAR) e tempo de agitação lenta (TAL) para a clarificação (a) e o volume de sólidos (b).

Em relação aos efeitos das variáveis isoladas, para o processo de clarificação (Figura 3a), tanto a velocidade de agitação rápida (AR) como a velocidade de agitação lenta (AL) apresentaram efeito significativo negativo, o que significa que a passagem do nível -1 para +1 do planejamento experimental leva a menores valores de percentuais de clarificação. Em relação ao processo, isto significa que a velocidade de agitação rápida que proporciona a coagulação e velocidade de agitação lenta, que leva a floculação, não podem ser excessivas, pois prejudicam o processo de formação e decantação dos flocos.

Segundo Vaz et al. (2010), a coagulação anula as forças de repulsão entre as partículas coloidais. Para que o processo de coagulação seja eficiente, este deve ser realizado por meio de agitação intensa (mistura rápida) para que ocorram interações entre o coagulante e a água (efluente). A floculação das partículas já coaguladas pela ação do eletrólito resulta das várias forças de atração que atuam entre as partículas "neutralizadas" que se agregam umas às outras formando os denominados flocos. A velocidade de formação desses flocos depende da agitação mecânica, que deve ser em nível moderado (mistura lenta), pois, do contrário, poderá provocar a desagregação dos flocos já formados.

Para o volume de sólidos (Figura 3b), apenas interação das variáveis, agitação rápida (AR) e agitação lenta (AL), apresentou efeito significativo positivo, o que significa que a passagem do nível -1 para +1 do planejamento experimental leva o maior valor para o volume de sólidos $(\mathrm{mL})$ decantados, ou seja, a combinação adequada de agitação rápida (AR) e agitação lenta (AL) contribui para o aumento da decantação de sólidos $(\mathrm{mL})$.

Em relação aos tempos de agitação rápida e de agitação lenta, verifica-se que, dentro da faixa testada, não exerceram efeito estatístico significativo ( $p>0,05)$. 
Tabela 3. Médias de Clarificação (\%) e volume de Sólidos Decantados (mL/200mL) para o efluente agroindustrial após o tratamento com extrato de Acácia Negra (Acácia mearnsii)

\begin{tabular}{|c|c|c|c|c|c|c|}
\hline $\begin{array}{l}\text { Experi- } \\
\text { mento }\end{array}$ & $\begin{array}{c}\text { Agitação } \\
\text { Rápida } \\
\text { (rpm) }\end{array}$ & $\begin{array}{c}\text { Agitação } \\
\text { Lenta } \\
\text { (rpm) }\end{array}$ & $\begin{array}{c}\text { Tempo } \\
\text { de } \\
\text { Agitação } \\
\text { Rápida } \\
\text { (min) }\end{array}$ & $\begin{array}{c}\text { Tempo } \\
\text { de } \\
\text { Agitação } \\
\text { Lenta } \\
\text { (min) }\end{array}$ & $\begin{array}{c}\text { Clarificação } \\
(\%)\end{array}$ & $\begin{array}{c}\text { Sólidos } \\
\text { decantados } \\
\text { (mL/200mL de } \\
\text { efluente) }\end{array}$ \\
\hline$\overline{E 1}$ & 230 & 120 & 7 & 10 & $32,73^{a} \pm 3,74$ & $45,67^{\mathrm{de}} \pm 2,08$ \\
\hline E2 & 230 & 120 & 3 & 10 & $34,13^{\mathrm{ab}} \pm 2,69$ & $46,33^{\mathrm{de}} \pm 1,53$ \\
\hline E3 & 230 & 80 & 7 & 30 & $40,33^{\mathrm{abcde}} \pm 2,44$ & $36,33^{b} \pm 1,53$ \\
\hline E4 & 170 & 120 & 3 & 30 & $41,43^{\text {bcde }} \pm 1,85$ & $39,33^{b c} \pm 0,58$ \\
\hline E5 & 230 & 80 & 3 & 30 & $36,43^{\mathrm{abc}} \pm 4,37$ & $43,00^{\mathrm{cd}} \pm 1,00$ \\
\hline E6 & 170 & 80 & 7 & 10 & $42,43^{\text {cde }} \pm 3,53$ & $52,33^{\mathrm{f}} \pm 1,53$ \\
\hline E7 & 170 & 120 & 7 & 30 & $44,73^{\mathrm{def}} \pm 2,93$ & $39,67^{\mathrm{bc}} \pm 0,58$ \\
\hline E8 & 170 & 80 & 3 & 10 & $41,43^{\text {bcde }} \pm 2,14$ & $48,33^{\mathrm{ef}} \pm 0,58$ \\
\hline E9 & 150 & 100 & 5 & 20 & $50,63^{\mathrm{g}} \pm 1,91$ & $40,67^{\mathrm{bc}} \pm 1,15$ \\
\hline E10 & 250 & 100 & 5 & 20 & $40,43^{\text {abcde }} \pm 1,69$ & $43,00^{\mathrm{cd}} \pm 2,65$ \\
\hline E11 & 200 & 66 & 5 & 20 & $45,83^{\mathrm{ef}} \pm 1,29$ & $45,33^{\mathrm{de}} \pm 1,15$ \\
\hline E12 & 200 & 134 & 5 & 20 & $37,43^{\mathrm{abcd}} \pm 2,37$ & $42,33^{\mathrm{cd}} \pm 1,53$ \\
\hline E13 & 200 & 100 & 1,6 & 20 & $44,23^{\text {cdef }} \pm 1,00$ & $49,67^{\mathrm{ef}} \pm 2,08$ \\
\hline E14 & 200 & 100 & 8,4 & 20 & $45,00^{\operatorname{def}} \pm 2,07$ & $46,33^{\text {de }} \pm 0,58$ \\
\hline E15 & 200 & 100 & 5 & 3 & $43,63^{\text {cdef }} \pm 3,97$ & $45,67^{\mathrm{de}} \pm 1,53$ \\
\hline E16 & 200 & 100 & 5 & 37 & $44,23^{\text {cdef }} \pm 2,76$ & $49,33^{\text {ef }} \pm 2,08$ \\
\hline E17 & 200 & 100 & 5 & 20 & $39,33^{\text {abcde }} \pm 0,91$ & $28,33^{a} \pm 0,58$ \\
\hline E18 & 200 & 100 & 5 & 20 & $39,33^{\text {abcde }} \pm 0,91$ & $28,33^{a} \pm 0,58$ \\
\hline
\end{tabular}

Médias seguidas de letras minúsculas diferentes, na coluna, diferem em nível de $95 \%$ de confiabilidade pelo Teste de Tukey $(\mathrm{p}<0,05)$.

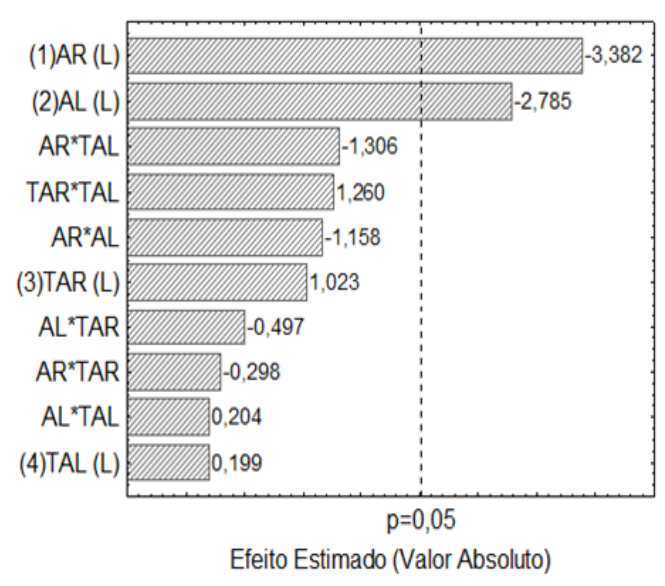

(a)

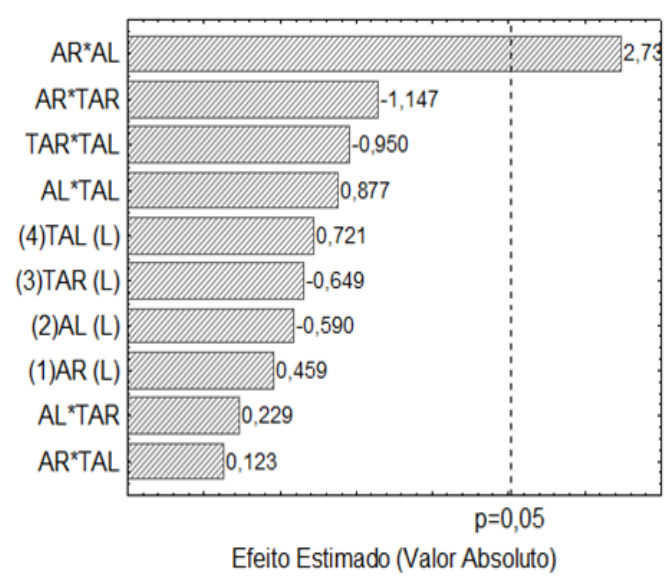

(b)

Figura 3. Diagramas de Pareto obtidos a partir dos resultados de Clarificação (a) e de Sólidos decantados (b) do efluente agroindustrial utilizando extrato de Acácia negra como coagulante.

Para a obtenção do modelo matemático que represente a clarificação e o volume de sólidos, considerando as variáveis $\mathrm{AR}$ e $\mathrm{AL}$, foram calculados os coeficientes de regressão. O modelo matemático empírico, obtido a partir dos coeficientes calculados, permitiu a construção das 
Superfícies de Resposta, sendo apresentadas na Figura 4 para a clarificação (a) $\left(R^{2}=0,9863\right)$ e para o volume de sólidos (b) $\left(\mathrm{R}^{2}=0,9776\right)$.

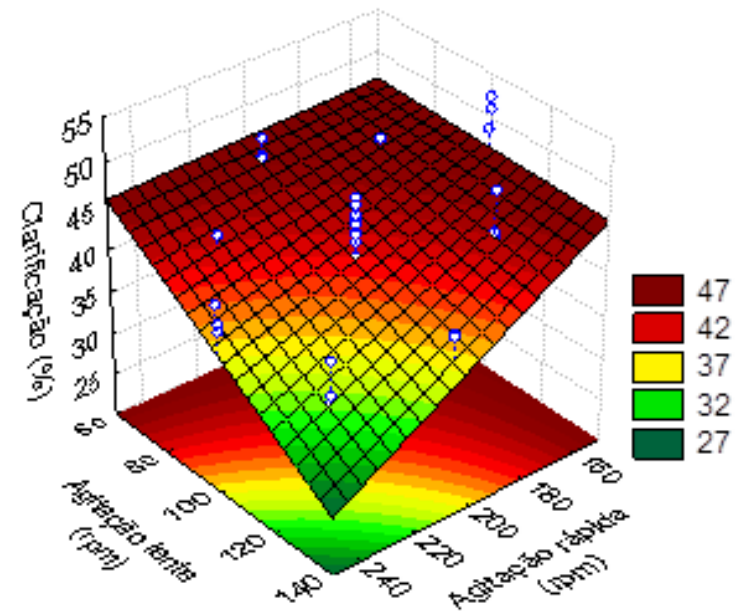

(a)

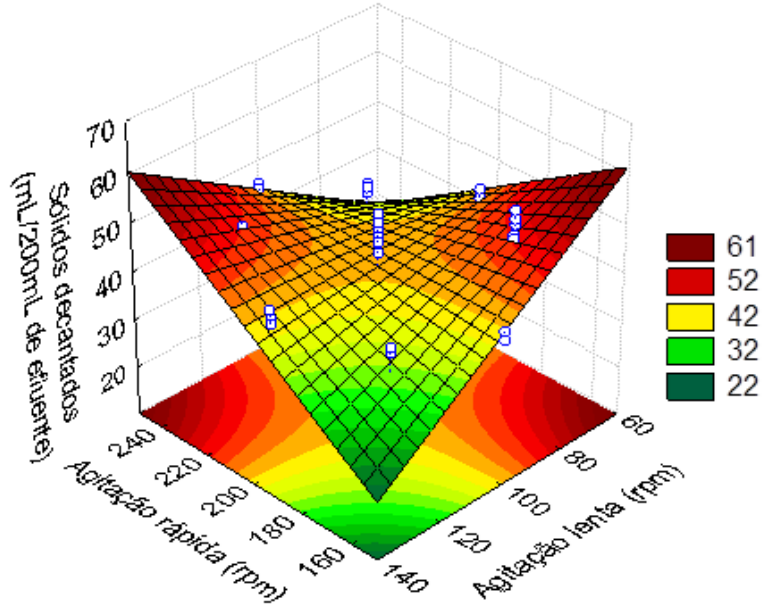

(b)

Figura 5. Superfícies de Respostas obtidas a partir dos resultados de Clarificação (a) e Sólidos decantados (b) do efluente agroindustrial utilizando extrato de Acácia negra como coagulante.

Observa-se que a região de maximização da clarificação (região em vermelho escuro), encontra-se amplamente distribuída na região superior da (Figura 4a), com valores de agitação lenta entre 60 e 80 rpm, de agitação rápida entre 150 e 180 rpm e clarificação de 42-47\%, onde velocidades de agitação rápida maiores, junto com velocidades de agitação lenta maiores, apresentam menor eficiência na clarificação. Portanto, para este processo, AR pode ser utilizada na faixa de 150 a 200 rpm e AL até 100 rpm, desde que combinada com AR abaixo de 200 rpm.

Para o volume de sólidos decantados, as regiões de máxima decantação (região em vermelho escuro), encontram-se nos cantos superiores esquerdo e direito, com valores de AL entre 60 e 80 rpm, de AR entre 220 e 240 rpm e sólidos decantados de 52-61mL, onde velocidades de agitação lenta maiores, junto com velocidades de agitação rápida menores, apresentam menor eficiência para os sólidos decantados.

Em estudos realizados por Pozzobon e Kempka, (2015) com sementes de Moringa oleifera para a remoção de turbidez de água, verificaram que máxima clarificação acontece quando utilizados 
valores de agitação entre 50 e 100 rpm, com remoção de 53,20\% concentração, remoção muito semelhante as verificadas no presente estudo.

Flores et al. (1998) utilizaram o tempo de agitação de 10 minutos à baixa velocidade $50 \mathrm{rpm}$ para melhor redução da concentração da variável cor real no efluente.

Em estudo realizado por Corala et al. (2009), para a remoção da turbidez, foi utilizada agitação rápida superior a $120 \mathrm{rpm}$ por 10 segundos e rotações abaixo de $50 \mathrm{rpm}$ para a fase de mistura lenta por 15 minutos, sendo que o Tanfloc (nome comercial de um coagulante obtido do extrato de Acácia Negra) demonstrou promover uma redução da turbidez mais rapidamente quando comparado com o sulfato de alumínio.

Atribui-se, como vantagem ao seu uso para o tratamento de água para consumo e para tratamento de efluentes industriais.

\section{Conclusões}

O extrato de Acácia negra (Acácia mearnsii) usado coagulante natural pode ser considerado uma alternativa para o tratamento de efluente de agroindústria. Os percentuais máximos de clarificação obtidos para os ensaios de concentração de coagulante foram $56,20 \%$ para a solução de extrato de Acácia negra a 1\% e 56,53\% para a solução de extrato de Acácia negra a 2\%.

No estudo da influência da velocidade e do tempo de agitação, mostraram que velocidades de agitação rápida maiores, junto com velocidades de agitação lenta maiores, apresentam menor eficiência na clarificação e que onde velocidades de agitação lenta maiores, junto com velocidades de agitação rápida menores, apresentam menos eficiência para o volume de sólidos decantados. Para este estudo, o tempo de agitação lenta e o tempo de agitação rápida, dentro da faixa testada, não apresentaram efeito sobre o processo.

\section{Referências}

CARDOSO, K. C., BERGAMASCA, R., COSSICH, E. S., MORAES, L. C. K. 2008. Otimização dos Tempos de Mistura e Decantação no Processo de Coagulação/Floculação da Água Bruta por Meio da Moringa oleífera Lam. Acta Scientiarum. Technology, 30 (2), 193-198.

CHOY, S. Y., PRASAD, K., WU, T. Y.; RAGHUNANDAN, M. E., RAMANAN, R. N. 2014. Utilization of Plant-based Natural Coagulants as Future Alternatives Towards Sustainable Water Clarification. Science Direct, 26 (11), 2178-2189.

CORALA, L. A., BERGAMASCO, R., BASSETTI, F. J. Estudo da Viabilidade de Utilização do Polímero Natural (TANFLOC) em Substituição ao Sulfato de Alumínio no Tratamento de Águas para Consumo. 2nd International Workshop Advances in Cleaner Production, 2009 São Paulo, Brasil. 20-22.

DE MARTINI, M. V. P., MORUZZI, R. B. 2013. Tratabilidade de Águas Pluviais Utilizando Coagulante Natural a

Base de Tanino Visando Fins não Potáveis. Teoria e Prática na Engenharia Civil, 22, 15-23.

EDVAN, R. L., CARNEIRO, M. S. S. 2011. Uso da Digesta Bovina como Adubo Orgânico. Revista Brasileira de Tecnologia Aplicada nas Ciências Agrárias, 4 (2), 211-225.

FLORES, D. M. M., FRIZZO, S. M. B., FOELKEL, C. E. B. 1998. Tratamentos Alternativos do Efluente de Uma Indústria de Celulose Branqueada e Papel. Ciência Florestal, Santa Maria, 8 (1), 93-107. 
LENHARI, J. L. B., HUSSAR, G. J. 2010. Comparação Entre o Uso da Moringa oleifera Lam e de Polímeros Industriais no Tratamento Físico-Químico do Efluente de Indústria Alimentícia. Revista Engenharia Ambiental, 7 (4), 33-42.

MATOS, A. T., CABANELLAS C. F. G., CECON, P. R., BRASIL, M. S., MUDADO, C. S. 2007. Efeito da Concentração de Coagulantes e do pH da Solução na Turbidez de Água, em Recirculação, Utilizada no Processamento dos Frutos do Cafeeiro. Eng. Agríc. Jaboticabal, 27 (2), 544-551.

MENDES, A. A., DE CASTRO, H. F., PEREIRA, E. B., FURIGO, A. J. 2005. Aplicação de Lipases no Tratamento de Águas Residuárias com Elevados Teores de Lipídeos. Química Nova, 28 (2), 296305.

PIANTÁ, C. A. V. 2008. Emprego de Coagulantes Orgânicos Naturais como Alternativa ao uso do Sulfato de Alumínio no Tratamento de Água. Trabalho de Diplomação, Universidade Federal do Rio Grande do Sul.

POZZOBON, L., KEMPKA. A. P. 2015. Sementes de Moringa Oleifera na Clarificação de Efluente de Indústria de Ingredientes para Alimentação Animal: Comparação com o Coagulante Convencional e Estudo das Condições Operacionais. Engevista, 17 (2), 196-206.

SANEPAR. 2004. Manual de ensaio de floculação. Curitiba, PR: Governo do Paraná, 33.

SCARASSATI, D., DE CARVALHO, R. F., DELGADO, V. L., CONEGLIAN, C. M. R., DE BRITO, N. N., TONSO, S., DRAGONI, G. S., PELEGRINI, R. Tratamento de Efluentes de Matadouros e Frigoríficos. III Forúm de Estudos Contábeis. 2003. Rio Claro, Brasil. 4-9.

VAZ, L. G., F KLEN, R. M., VEIT, T. M., SILVA, A. E., BARBIERO, A. T., BERFAMASCO, R. 2010. Avaliação da Eficiência de Diferentes Agentes Coagulantes na Remoção de Cor e Turbidez em Efluente de Galvanoplastia. Eclética Química, 35 (4).

ZOLETT, E. R., JABUR, A. S., SILIPRNDI, E. M. Uso de Polímero Natural a Base de Tanino (TANFLOC) para o Tratamento de Água para o Consumo Humano. XVII Seminário de Iniciação Científica e Tecnológica da Universidade Tecnológica do Paraná.

2012. Curitiba, Brasil. 